\title{
Adiabatic shear localization in Nanostructured face centered cubic metals under uniaxial compression Jianguo $\mathrm{Li}^{\mathrm{a}, \mathrm{b}}$, Tao Suo ${ }^{\mathrm{a}, \mathrm{b}^{*}}$, Chongxiang Huang ${ }^{\mathrm{c}^{*}}$, Yulong $\mathrm{Li}^{\mathrm{a}, \mathrm{b}}$, Hongtao Wang ${ }^{\mathrm{d}}$, Jiabin Liu ${ }^{\mathrm{e}}$
}

${ }^{a}$ Fundamental Science on Aircraft Structural Mechanics and Strength Laboratory, Northwestern Poly-technical University, Xi'an 710072, Shaanxi, PR China

${ }^{\mathrm{b}}$ School of Aeronautics, Northwestern Polytechnical University, Xi' an 710072, China

${ }^{\mathrm{c}}$ School of Aeronautics and Astronautics, Sichuan University, Chengdu 610065, China

${ }^{\mathrm{d}}$ Institute of Applied Mechanics, Zhejiang University, Hangzhou 310027, China

${ }^{\mathrm{e}}$ Department of Materials Science and Engineering, Zhejiang University, Hangzhou 310027, China

* Corresponding authors

Email: suotao@nwpu.edu.cn, chxhuang@scu.edu.cn

Fax: $+862988491208 \quad$ Phone: +862988494859

\begin{abstract}
In this work, the dynamic behavior of nanostructured $\mathrm{Cu}-11.14 \% \mathrm{Al}$ alloy with face-centered cubic (FCC) structure has been investigated using split Hopkinson pressure bar. At high strain rate uniaxial compression (strain rate $\sim 4 \times 10^{3} \mathrm{~s}^{-1}$ ), a sharp stress collapse was observed in the plastic regime of the specimens. Post-loading examinations verified the appearance of adiabatic shear band (ASB), which has rarely been observed in FCC metals under uniaxial loading. Adiabatic heating within the ASBs has led to recrystallization, resulting in remarkably refined and defect-free nanocrystalline grains. The occurrence of ASBs in such an FCC alloy can be explained based on established mechanistic models.
\end{abstract}

Key words: nanostructured; FCC structure; Hopkinson bar; adiabatic shear band. 


\section{Introduction}

The plastic deformation of nanostructured (NS) or ultrafine grained (UFG) materials has attracted tremendous attention in the past decades [1]. Severely localized deformation has been reported in some NS or UFG metals, particularly under high strain rate (dynamic) loading [2]. Typically this localization is manifested by the appearance of very narrow shear bands under dynamic compression [3, 4]. The global stress-strain response is usually characterized by elastic-perfectly plastic behavior, or by obvious strain softening under dynamic loading condition. Moreover, the post-loading microstructural observation of the shear band has also revealed some interesting characteristics. A wide range of microstructure has been identified depending on the specific materials, indicative of processes such as recovery, static or dynamic recrystallization, grain refinement, and so on, as a result of the severe shear deformation inside the localized narrow band. However, most investigations on shear bands in NS materials focused on metals with body centered cubic (BCC) and hexagonal close-packed (HCP) lattice structures. For example, adiabatic or non-adiabatic shear bands were observed by Wei et al. [5-9] in W, V, Ta and Fe etc. under dynamic or quasi-static loading. They attributed the localization in plasticity to the decreased strain rate sensitivity (SRS) with refined grain size to UFG or NS regime as well has much elevated yield strength and vanishingly small strain hardening in those metals. In $\mathrm{HCP}$ metals, such as $\mathrm{Ti}$ and $\mathrm{Mg}$ alloys [10, 11], considerable adiabatic temperature rise during high strain rate loading leads to the 
initiation of shear localization. However, in UFG or NS face centered cubic (FCC) metals no such observations have been reported except for specimens with special geometry, such as the hat-shaped or truncated cone geometry that artificially introduces a concentrated large shear stress in certain local regions $[12,13]$. Such specimen geometry can give rise to shear localization in any visco-plastic material, though it does not measure the "intrinsic" propensity of the material for adiabatic shear banding[14].

In this work, adiabatic shear bands (ASBs) were observed in NS Cu-11.14\% Al specimens under uniaxial compressive loading at high strain rate of $4 \times 10^{3} \mathrm{~s}^{-1}$ by the split Hopkinson pressure bar (SHPB) technique. Since the alloy is of FCC structure, we believe this is the first report on the occurrence of ASB in NS/UFG FCC metals and alloys under such loading condition. As such, it is believed that this may shed light on the understanding of the mechanical properties, particularly high strain rate behavior of NS/UFG metals with FCC structure. A reasonable interpretation of the experimental results can be provided based on a mechanistic model available in the literature.

\section{Experiments}

In this work, a $\mathrm{Cu}-11.14$ at. \% $\mathrm{Al}$ was processed and investigated in terms of its microstructure and mechanical behavior, particularly high strain rate behavior. Henceforth the alloy will be denoted as $\mathrm{Cu}-11.14 \mathrm{Al}$ for simplification. The alloy was processed by equal channel angular pressing (ECAP) for 8 passes in route $B_{C}$ at 
room temperature (RT). The processing details can be found in reference [15]. For quasi-static and dynamic mechanical testing, samples with dimension of $3 \times 3 \times 3 \mathrm{~mm}^{3}$ were machined from the worked part of the ECAP billets. The quasi-static compression tests (at strain rates of $5 \times 10^{-4} \mathrm{~s}^{-1}$ and $1 \times 10^{-2} \mathrm{~s}^{-1}$ ) were carried out with a CSS44100 electro-mechanical universal testing machine. The split Hopkinson pressure bar (SHPB) was employed for dynamic loading at strain rates of $1 \times 10^{3}$ and $4 \times 10^{3} \mathrm{~s}^{-1}$. The primary components of this SHPB system are three steel bars: a striker bar, an incident bar and a transmission bar. The diameter of all the bars are $12.7 \mathrm{~mm}$. When the striker bar launched from a gas gun impacts the free end of the incident bar, a compressive pulse is generated and travels along the incident bar towards the specimen. Due to the mismatch of wave impedance between the specimen and loading bars, while reaching the bar/specimen interfaces, part of stress pulse is reflected and another part is transmitted into the transmission bar. The pulses are captured by strain gauges attached to the elastic bars. According to the one dimensional elastic wave theory [16], the strain, stress and strain rate of tested specimen can be calculated. In order to analyze $\mathrm{SRS}$ of $\mathrm{NS} \mathrm{Cu}-\mathrm{Al}$ alloys strain rate jump tests under quasi-static compression were also performed at RT. During the jump test, repeated loading, unloading and reloading is used to observe the effect of strain rate jumps on the flow stress. The loading rate was changed four times from $5 \times 10^{-4} \mathrm{~s}^{-1}$ to $1 \times 10^{-2} \mathrm{~s}^{-1}$ by controlling the cross-head speed [17][25,29]. Meanwhile, to quantitatively analyze the temperature sensitivity, experiments were 
also performed at the temperature ranging from RT to $300^{\circ} \mathrm{C}$ at a strain rate of $4 \times 10^{3}$ $\mathrm{s}^{-1}$ by using a modified SPHB apparatus where a synchronically assembled heating system was added. The common approach to high-temperature dynamic experiment is simply heating the specimen which is in contact with the incident and transmission bars. As such, part of the bars is in the heating furnace. However, the synchronic loading technique enables us to preheat the specimen while the incident and transmission bars are kept out of the furnace. The specimen was separately heated to the desired temperature in the furnace and this condition was maintained for 1 minute to ensure a homogeneous distribution within the specimen. Afterwards, the elastic bars are brought into contact with the specimen by the synchronically assemble system before the stress pulse reaches the interface between the incident bar and the specimen. More details of this system can be found in this reference [18]. All dynamic compression tests were conducted in Northwestern Polytechnical University. To ensure validity and repeatability of the experimental results, at least three tests were performed for each condition.

After deformation, the sample surface parallel to the loading direction was examined by optical microscopy (OM) and scanning electronic microscopy (SEM). The microstructures inside and outside ASBs were observed by a JEM 2000 FX transmission electron microscope (TEM) operated at $200 \mathrm{kV}$. The TEM foils cut from the post-tested sample were prepared by focused ion beam (FIB) technique at three different places (inside/beside/outside the ASB). The foils is thin enough to be 
observed directly. In contrast, the TEM foil cut from as-ECAPed material were firstly ground to $60 \mu \mathrm{m}$ using 4000 grit $\mathrm{SiC}$ polishing paper and then thinned by ion milling.

\section{Results and discussion}

Figs. 1(a) and (b) show the typical bright and dark-field TEM images of the as-ECAPed NS Cu-11.14Al alloy. The microstructure is characterized by equiaxed nano-grains with sharp boundaries and the average grain size is $\sim 93 \mathrm{~nm}$. Some deformation twins and stacking faults can be observed within the nano-grains, as indicated by the red arrows.

Fig. 2(a) presents the typical stress-strain curves at different strain rates. It is worth explaining that the maximum strains at high strain rates are limited by the duration of loading pulse in SHPB. Therefore, the specimens tested at the strain rate of $1 \times 10^{3} \mathrm{~s}^{-1}$ were only compressed to true strain less than $20 \%$. No cracks were observed for almost all specimens except for that deformed at $4 \times 10^{3} \mathrm{~s}^{-1}$. Slight strain hardening was observed at relatively low strain rate (less than $0.01 \mathrm{~s}^{-1}$ ), which is probably due to the presence of deformation twins and stacking faults. However, remarkable strain softening occurs at high strain rate of $4 \times 10^{3} \mathrm{~s}^{-1}$ and the total true strain approaches $\sim 0.35$. Stress collapse happens instantaneously, presumably indicating plastic instability. Observations of the surface of the post-loading high-strain rate specimen show several shear bands with the orientation at an angle of about $45^{\circ}$ with respect to the loading direction, as shown in Fig. 2(b). It is seen that 
the primary shear bands have developed on two conjugated surfaces, subsequently leading to cracks.

The flow stress softening in NS materials can be attributed to adiabatic heating. For current NS Cu-11.14Al alloy, a yield stress above $1.1 \mathrm{GPa}$ is achieved. The adiabatic temperature rise $\Delta \mathrm{T}$ for overall specimen under dynamic compression is estimated to be about $150 \mathrm{~K}$ at strain of 0.5 , according to

$$
\Delta T=\frac{\beta}{\rho C_{V}} \int_{0}^{\varepsilon_{f}} \sigma d \varepsilon
$$

where $\sigma$ the true stress, $\varepsilon_{f}$ the final strain, $\beta$ is a constant that represent the fraction of mechanical energy converted into heat, and is usually taken to be 0.9 for SHPB experiments [19]. $\rho$ is the density of material, $C_{V}$ the specific heat of $\mathrm{Cu}-\mathrm{Al}$ alloy. It is necessary to point out that the heat capacity varies with temperature rise. For $\mathrm{Cu}-11.14$ at. $\% \mathrm{Al}, C_{V}$ is $408 \mathrm{~J} / \mathrm{Kg} \cdot \mathrm{K}$ at room temperature and $430 \mathrm{~J} / \mathrm{Kg} \cdot \mathrm{K}$ at $450 \mathrm{~K}$, respectively. Therefore, the estimated temperature rise ranges from $147 \mathrm{~K}$ to $155 \mathrm{~K}$. Since the flow stress of UFG and NS FCC metals is very sensitive to temperature [20], such high adiabatic temperature rise can result in apparent softening observed here. The effect of temperature on flow stress was investigated in this work and the following statement will show the details.

Fig. 3(a) displays SEM micrograph showing the crack initiation from ASBs. The magnified pictures in Figs. 3(b) and (c) show the very large localized shear flow under dynamic loading. The ASB is about $15 \mu \mathrm{m}$ in width. Crack usually initiates 
from the boundary of ASB, as shown in Fig. 3(c). The microstructure in the interior of ASB is examined by TEM. As shown in Fig. 3(d), the grains inside ASB are characterized by equiaxed shape, sharp grain boundaries and very small grain size usually less than $50 \mathrm{~nm}$, which are more probably a result of dynamic recrystallization during the adiabatic shearing deformation [21]. However, the grains far away from ASB are found to be much larger and featured with high density of dislocations, twins and stack faults, as shown in Fig. 3(e). The above observations are typical characteristics induced by adiabatic shear localization, which is commonly observed in UFG/NS materials with BCC structure under uniaxial dynamic compression. But it has seldom been reported in UFG/NS materials with FCC structure. Therefore, a reasonable explanation of the occurrence of ASB in UFG/NS metals with FCC structure, such as observed in this work, is needed. Numerical analysis of Guo and co-workers [22] provides some explanation as to why UFG/NS BCC metals tend to exhibit plastic instability under dynamic loading, and conclude that UFG/NS FCC metals tend to be more resistant to dynamic plastic instability. In what follows we will attempt to provide some theoretical analysis of the results of this work.

To analyze the formation of adiabatic shear localization in $\mathrm{NS} \mathrm{Cu}-\mathrm{Al}$ alloy, the susceptibility to adiabatic shear localization was introduced as discussed for BCC and HCP metals. Wright $[23,24]$ described the related factors quantitatively by

$$
\frac{\chi_{A S B}}{a / m}=\min \left\{1, \frac{1}{n / m+\sqrt{n / m}}\right\}
$$


where $\chi_{A S B}$ represents the susceptibility to ASB, $a$ is the non-dimensional thermal softening parameter defined as $a=(-\partial \sigma / \partial T) \hat{\sigma}_{0} / \rho C_{V}, \hat{\sigma}_{0}$ is a characteristic stress, $\rho$ and $C_{V}$ are the density and specific heat capacity, respectively. In Eq. (2), $n$ is the strain hardening exponent and $m$ is the strain rate sensitivity (SRS) of the material. For UFG/NS metals produced by severe plastic deformation, strain hardening rate is usually small due to the poor capability to store up dislocations [25]. If strain hardening rate is neglected, as is the case for most UFG/NS metals and alloys, the above equation can be re-written as [5, 26],

$$
\chi_{A S B}=\frac{\lambda \sigma_{0}}{\rho C_{V} m}
$$

where $\lambda=-\partial \sigma \partial \mathrm{T}$ is defined as the temperature sensitivity factor. Eq. (3) indicates that the susceptibility to adiabatic shear localization for UFG/NS metals with vanishing strain hardening is the competition between temperature sensitivity and SRS of the flow stress. For UFG/NS metals with FCC structure, it is reported that both temperature sensitivity and SRS are enhanced compared with their coarse-grain counterparts [20, 27, 28].

To evaluate the SRS for NS Cu-11.14Al alloy, the strain rate jump tests were carried out between $5 \times 10^{-4}$ and $1 \times 10^{-2} \mathrm{~s}^{-1}$ at RT (see in Fig.4 (a)). The SRS factor was calculated according to

$$
m=\frac{\partial \ln \sigma}{\partial \ln \dot{\varepsilon}},
$$

where $\sigma$ is the flow stress and $\dot{\varepsilon}$ is the strain rate. The average SRS $m$ value is measured to be 0.0197 for NS Cu-11.14Al, as shown in Fig.4 (b). For comparison 
purpose, the SRS factor also is calculated based on the true stress-strain curves in the wide range of strain rate from $5 \times \overline{\times} 10^{-4} \mathrm{~s}^{-1}$ to $4 \times 10^{3} \mathrm{~s}^{-1}$ (this is called as constant strain rate method). The flow stresses used in the equation correspond to true strain $\overline{\varepsilon=0.1}$. The result also is shown in Fig.4 (b). Huang [29] measured the SRS of CG and NS $\mathrm{Cu}-11.1 \mathrm{Al}$ to be 0.0036 and 0.0187 by stress relaxation, which is close to our measurement. It means that the flow stress of $\mathrm{NS} \mathrm{Cu}-\mathrm{Al}$ alloy with low stacking fault energy (SFE) is still strong rate-dependent as similar as other NS FCC metals [30].

As to the temperature sensitivity, it is reported that the increase in temperature sensitivity is due to the reduction in activation volume of nanocrystalline metals [28, 31]. In this work, the dynamic properties of $\mathrm{NS} \mathrm{Cu}-11.14 \mathrm{Al}$ alloy at different temperatures are shown in Fig. 4(c). The temperature sensitivity factor $\lambda$ is calculated and shown by the inset of Fig. 4 (c). The susceptibility to ASB for NS Cu-11.14Al is estimated to be $\sim 1.74 \times 10^{4}$ by using the following parameters $\sigma_{0}=1.1 \mathrm{GPa}, \mathrm{m}=0.02$ and $\lambda=1.03$. For $\mathrm{CG} \mathrm{Cu}-\mathrm{Al}$ alloy, based on the experimental data reported in Reference [32], $n=0.716$ and $m=0.01$, Eq. (2) can be written as $\chi_{A S B}=0.0125 a / m$. By using $\sigma_{0}=150 \mathrm{MPa}$, the resulting $\chi_{A S B}$ for the coarse-grain counterpart is only $\sim 11.5$. Obviously, the susceptibility to ASB for NS Cu-Al alloy is three orders of magnitude higher than that of its coarse grain counterpart. This can at least partially explain the occurrence of ASBs in the NS Cu-11.14Al alloy.

We envisage that due to the effects of much elevated flow strength and the diminishing role of the stabilizing mechanism of strain hardening at high strain rate, 
this kind of NS FCC microstructure has low resistance to softening mechanism. As a consequence, plastic flow will be more likely to localize. In this work, localized flow and subsequent cracking are indeed observed upon uniaxial dynamically compressive loading. For $\mathrm{Cu}-11.14 \mathrm{Al}$ with low stacking fault energy, deformation twinning and twin fragmentation can refine the grain size to several ten nanometers during severe plastic deformation [15]. The grain size strengthening and solid solution hardening concurrently lead to such a high strength. As shown in Fig. 2(a), NS Cu-11.14Al still presents slight work hardening when the specimen is loaded under quasi-static condition. However, at high strain rate the strength further enhances because of the strong strain rate hardening and the strain hardening behavior disappears, the flat plastic flow shows the competition between strain hardening and softening mechanism, as stated by Zener and Hollomon [33]. Under dynamic loading there is no enough time for the heat induced by plastic deformation to diffuse through the specimen. Besides, with the grain refinement NS/UFG FCC metals show a stronger temperature dependence of flow stress [27][34]. In Fig.4 (c), when the temperature increases by $75 \mathrm{~K}$, the flow stress decreases by about $100 \mathrm{MPa}$. It can also be seen that the flow stress decreases to the stress level at temperature of $373 \mathrm{~K}$ when the true strain is about 0.45 . By calculating the temperature rise at this point it can be found that the global temperature rise has already been much higher. Therefore, thermal softening might be an important factor that causes localized shearing in the NS FCC $\mathrm{Cu}-\mathrm{Al}$ alloy. 


\section{Conclusion}

In summary, the mechanical properties of NS Cu-11.14Al alloy with low SFE was investigated at strain rates from $5 \times 10^{-4} \mathrm{~s}^{-1}$ to $4 \times 10^{3} \mathrm{~s}^{-1}$. Strain hardening was found under quasi-static loading conditions, while strain softening occurred at high strain rate of $4 \times 10^{3} \mathrm{~s}^{-1}$ by using specimens with common cubic geometry. Adiabatic shear bands were observed in the deformed specimens. Compared with the coarse grain counterpart, the susceptibility to ASB for NS $\mathrm{Cu}-\mathrm{Al}$ alloy has increased by three orders of magnitude because of the much elevated strength and the increased temperature sensitivity, which combined together outplay the increased strain rate sensitivity and render the occurrence of adiabatic shear bands under uniaxial dynamic compression. This, according to our knowledge, is the first report on the formation of adiabatic shear bands in FCC NS metals under uniaxial compression. Based on the existing experimental result, thermal softening might be an important factor that results into the formation of $\mathrm{ASB}$ in $\mathrm{NS} \mathrm{Cu}-\mathrm{Al}$ alloy. But more research still needs to be done to explain the formation mechanism in depth.

\section{Acknowledge}

This work was performed under the financial support from the National Science Foundation of China (grant Nos. 11522220, 11272267 and 11172187), 111 Project (grant No.B07050) of Northwestern Poly-technical University, and the Program for New Century Excellent Talents in University (NCET-12-0372). 


\section{References}

[1] K.S. Kumar, H. Van Swygenhoven, S. Suresh,Mechanical behavior of nanocrystalline metals and alloys, Acta Mater, 51 (2003) 5743-5774.

[2] M.A. Meyers, A. Mishra, D.J. Benson, Mechanical properties of nanocrystalline materials, Progress in Materials Science, 51 (2006) 427-556.

[3] Y. Xu, J. Zhang, Y. Bai, M.A. Meyers,Shear Localization in Dynamic Deformation: Microstructural Evolution, Metall and Mat Trans A, 39 (2008) 811-843.

[4] D. Xing, Y.L. Bai, C.M. Cheng, X.L. Huang,On Post-Instability Processes in Adiabatic Shear in Hot Rolled Steel, Journal of the Mechanics and Physics of Solids, 39 (1991) 1017-1042.

[5] Q. Wei, L. Kecskes, T. Jiao, K.T. Hartwig, K.T. Ramesh, E. Ma,Adiabatic shear banding in ultrafine-grained Fe processed by severe plastic deformation, Acta Mater, 52 (2004) 1859-1869.

[6] Q. Wei, D. Jia, K.T. Ramesh, E. Ma,Evolution and microstructure of shear bands in nanostructured Fe, Applied Physics Letters, 81 (2002) 1240-1242.

[7] Q. Wei, T. Jiao, K.T. Ramesh, E. Ma, L.J. Kecskes, L. Magness, R. Dowding, V.U. Kazykhanov, R.Z. Valiev,Mechanical behavior and dynamic failure of high-strength ultrafine grained tungsten under uniaxial compression, Acta Mater, 54 (2006) 77-87.

[8] Q. Wei, T. Jiao, S.N. Mathaudhu, E. Ma, K.T. Hartwig, K.T. Ramesh,Microstructure and mechanical properties of tantalum after equal channel angular extrusion (ECAE), Mat Sci Eng a-Struct, 358 (2003) 266-272.

[9] Q. Wei, T. Jiao, K.T. Ramesh, E. Ma,Nano-structured vanadium: processing and mechanical properties under quasi-static and dynamic compression, Scripta Materialia, 50 (2004) 359-364.

[10] D.R. Chichili, K.T. Ramesh, K.J. Hemker,Adiabatic shear localization in alpha-titanium: experiments, modeling and microstructural evolution, Journal of the Mechanics and Physics of Solids, 52 (2004) 1889-1909.

[11] D. Rittel, Z.G. Wang,Thermo-mechanical aspects of adiabatic shear failure of AM50 and Ti6Al4V alloys, Mechanics of Materials, 40 (2008) 629-635.

[12] M.A. Meyers, U.R. Andrade, A.H. Chokshi,The Effect of Grain-Size on the High-Strain, High-Strain-Rate Behavior of Copper, Metall Mater Trans A, 26 (1995) 2881-2893.

[13] A. Mishra, M. Martin, N.N. Thadhani, B.K. Kad, E.A. Kenik, M.A. Meyers,High-strain-rate response of ultra-fine-grained copper, Acta Mater, 56 (2008) 2770-2783.

[14] L.S. Magness,High-Strain Rate Deformation Behaviors of Kinetic-Energy Penetrator Materials during Ballistic Impact, Mechanics of Materials, 17 (1994) 147-154.

[15] C.X. Huang, W. Hu, G. Yang, Z.F. Zhang, S.D. Wu, Q.Y. Wang, G. Gottstein,The effect of stacking fault energy on equilibrium grain size and tensile properties of nanostructured copper and copper-aluminum alloys processed by equal channel 
angular pressing, Mat Sci Eng a-Struct, 556 (2012) 638-647.

[16] H. Kolsky,An Investigation of the Mechanical Properties of Materials at very High Rates of Loading, Proceedings of the Physical Society. Section B, 62 (1949) 676.

[17] F.H. Dalla Torre, E.V. Pereloma, C.H.J. Davies,Strain hardening behaviour and deformation kinetics of $\mathrm{Cu}$ deformed by equal channel angular extrusion from 1 to 16 passes, Acta Mater, 54 (2006) 1135-1146.

[18] Y.L. Li, Y.Z. Guo, H.T. Hu, Q. Wei,A critical assessment of high-temperature dynamic mechanical testing of metals, Int J Impact Eng, 36 (2009) 177-184.

[19] M.A. Meyers, G.T. Gray, N.N. Thadhani,The Dynamic Behavior of Materials: An Introduction, Jom-Us, 62 (2010) 14-15.

[20] T. Suo, Y.L. Li, F. Zhao, X.L. Fan, W.G. Guo,Compressive behavior and rate-controlling mechanisms of ultrafine grained copper over wide temperature and strain rate ranges, Mechanics of Materials, 61 (2013) 1-10.

[21] M.A. Meyers, V.F. Nesterenko, J.C. LaSalvia, Q. Xue,Shear localization in dynamic deformation of materials: microstructural evolution and self-organization, Mat Sci Eng a-Struct, 317 (2001) 204-225.

[22] Y.Z. Guo, Y.L. Li, Z. Pan, F.H. Zhou, Q. Wei,A numerical study of microstructure effect on adiabatic shear instability: Application to nanostructured/ultrafine grained materials, Mechanics of Materials, 42 (2010) 1020-1029.

[23] T.W. Wright,The physics and mathematics of adiabatic shear bands, Cambridge: Cambridge Press, (2002).

[24] T.W. Wright,Shear band susceptibility: Work hardening materials, International Journal of Plasticity, 8 (1992) 583-602.

[25] Y.M. Wang, E. Ma,Strain hardening, strain rate sensitivity, and ductility of nanostructured metals, Mat Sci Eng a-Struct, 375 (2004) 46-52.

[26] T.W. Wright,Shear Band Susceptibility - Work-Hardening Materials, International Journal of Plasticity, 8 (1992) 583-602.

[27] T. Suo, Y.Z. Chen, Y.L. Li, C.X. Wang, X.L. Fan,Strain rate sensitivity and deformation kinetics of ECAPed aluminium over a wide range of strain rates, Mat Sci Eng a-Struct, 560 (2013) 545-551.

[28] T. Suo, L. Ming, F. Zhao, Y.L. Li, X.L. Fan,Temperature and Strain Rate Sensitivity of Ultrafine-Grained Copper under Uniaxial Compression, Int J Appl Mech, 5 (2013).

[29] C.X. Huang, W.P. Hu, Q.Y. Wang,Strain-rate sensitivity, activation volume and mobile dislocations exhaustion rate in nanocrystalline $\mathrm{Cu}-11.1$ at\% $\mathrm{Al}$ alloy with low stacking fault energy, Mat Sci Eng a-Struct, 611 (2014) 274-279.

[30] Q. Wei, S. Cheng, K.T. Ramesh, E. Ma,Effect of nanocrystalline and ultrafine grain sizes on the strain rate sensitivity and activation volume: fcc versus bcc metals, Mat Sci Eng a-Struct, 381 (2004) 71-79.

[31] T. Suo, Y.L. Li, K. Xie, F. Zhao, K.S. Zhang, Y.Y. Liu, The effect of temperature on mechanical behavior of ultrafine-grained copper by equal channel angular pressing, 
Mat Sci Eng a-Struct, 527 (2010) 5766-5772.

[32] A. Rohatgi, K.S. Vecchio, G.T. Gray, The influence of stacking fault energy on the mechanical behavior of $\mathrm{Cu}$ and $\mathrm{Cu}-\mathrm{Al}$ alloys: Deformation twinning, work hardening, and dynamic recovery, Metall Mater Trans A, 32 (2001) 135-145.

[33] C. Zener, J.H. Hollomon,Effect of strain rate upon plastic flow of steel, Journal of Applied Physics, 15 (1944) 22-32.

[34] Y.M. Wang, E. Ma, R.Z. Valiev, Y.T. Zhu,Tough nanostructured metals at cryogenic temperatures, Adv Mater, 16 (2004) 328-331.

Fig. 1 TEM microstructure of NS Cu-11.14Al produced by ECAP for 8passes at RT: (a) Bright-field micrograph, (b) corresponding dark-field micrograph.

(a)

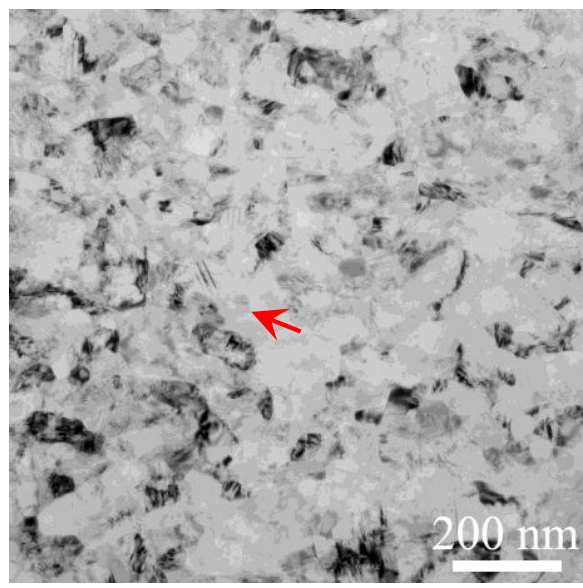

(b)

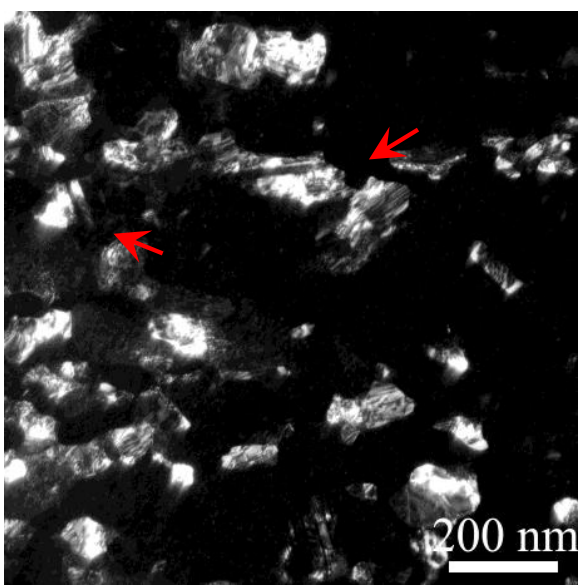


Fig. 2 (a) Typical true stress-strain curves of NS Cu-11.14Al in a wide range of strain rate from $5 \times 10^{-4} \mathrm{~s}^{-1}$ to $4 \times 10^{3} \mathrm{~s}^{-1}$ (b) OM image showing ASBs after dynamic loading.

(a)

(b)
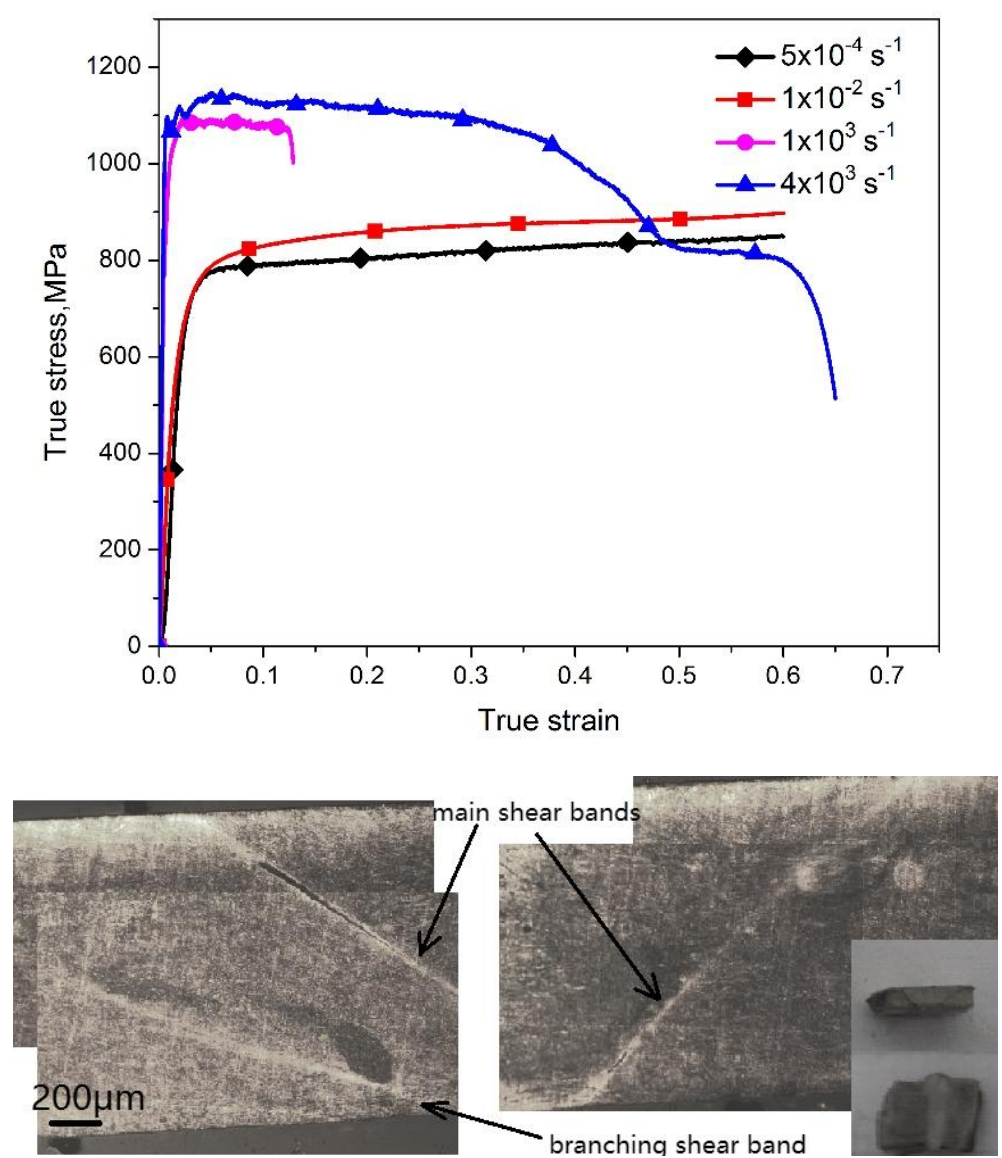
Fig. 3 Micrographs of adiabatic shear bands: (a) SEM micrograph showing ASBs and crack initiation, (b) enlarged image of the white rectangle area A in (a), (c) enlarged image of the white rectangle area B in (a), (d) TEM micrograph showing the grains inside ASB, (e) TEM micrograph showing the grains outside ASB
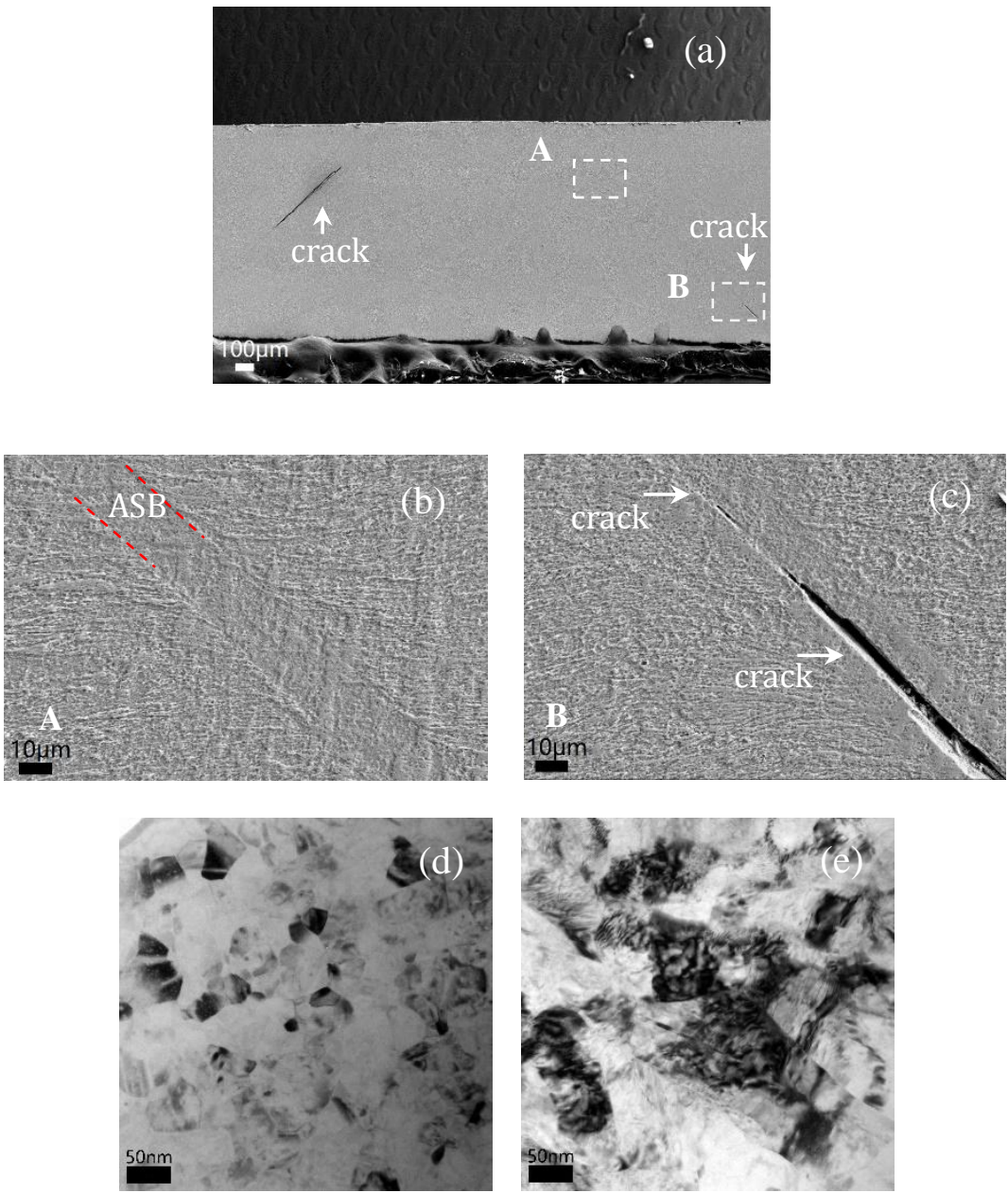
Fig. 4 (a) True stress-strain curves by strain rate jump tests for NS Cu-11.14Al. The inset picture shows the four strain rate jumps from $5 \times 10^{-4} \mathrm{~s}^{-1}$ to $1 \times 10^{-2} \mathrm{~s}^{-1}$. (b) Strain rate sensitivity of NS Cu-11.14Al alloy tested by strain rate jump test and constant strain rate method. (c) Typical true strain-stress curves loaded at different temperature (the strain rate of $4 \times 10^{3} \mathrm{~s}^{-1}$ ), and the inset image is the result of temperature sensitivity for $\mathrm{NS} \mathrm{Cu}-11.14 \mathrm{Al}$

(a)

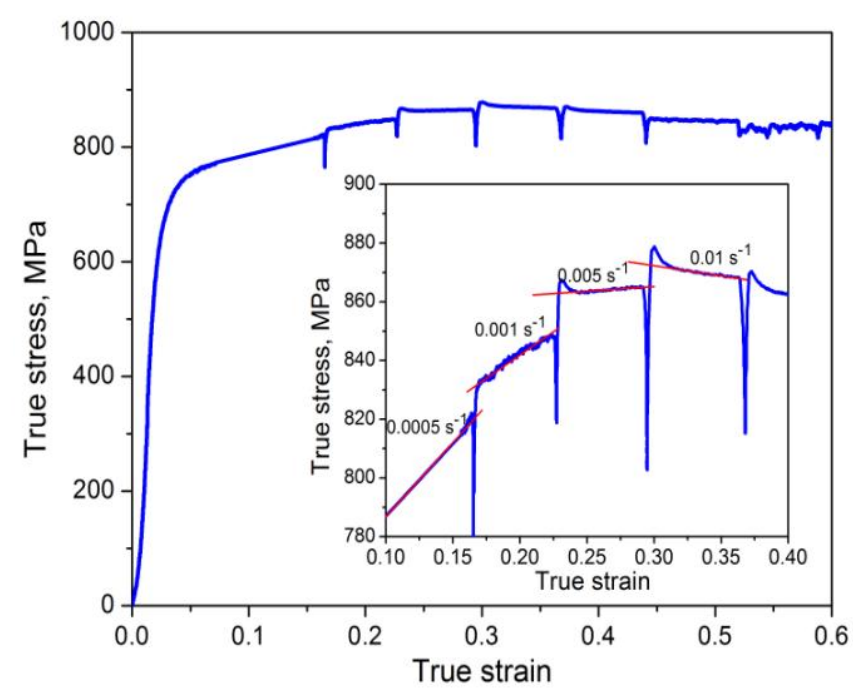

(b)

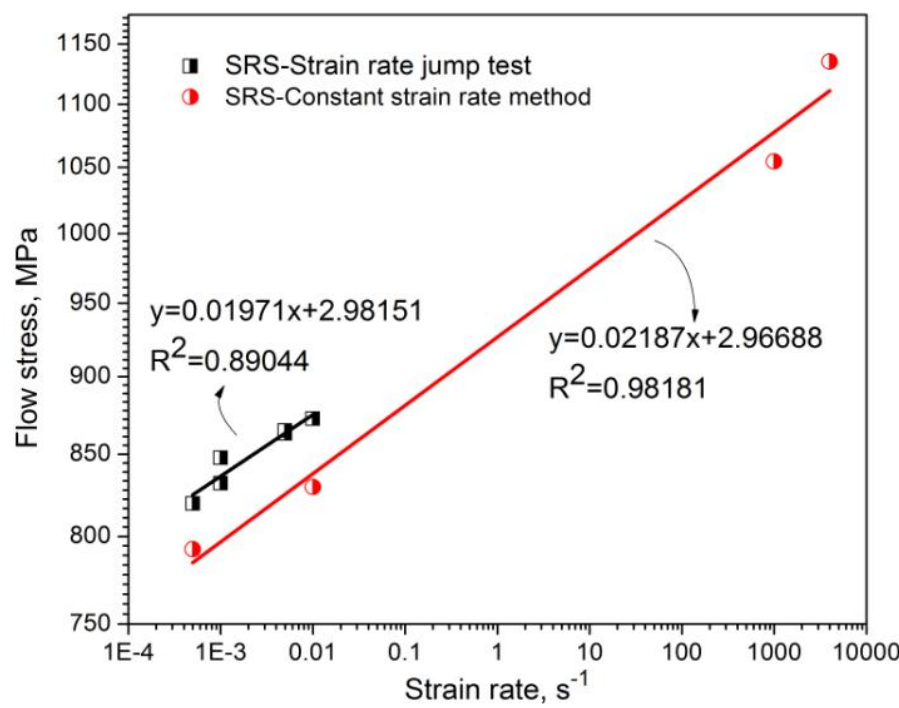


(c)

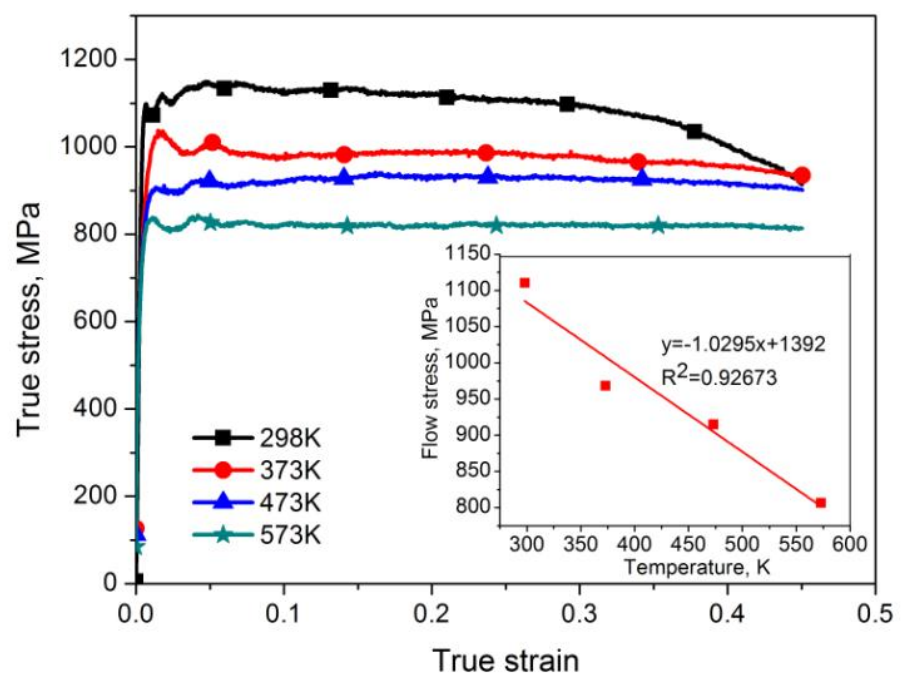



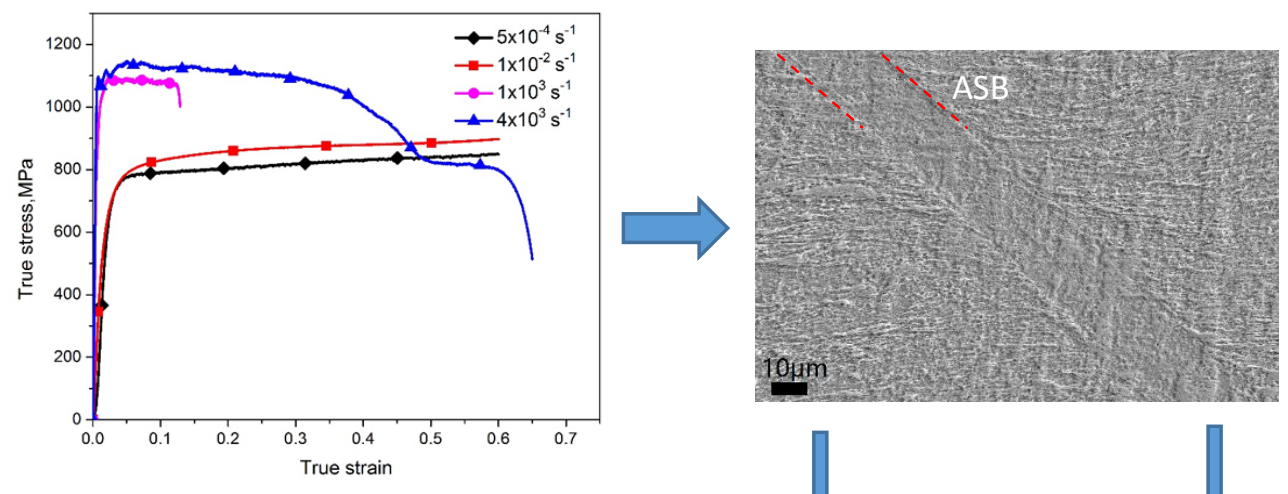

Outside the ASB

Inside the ASB

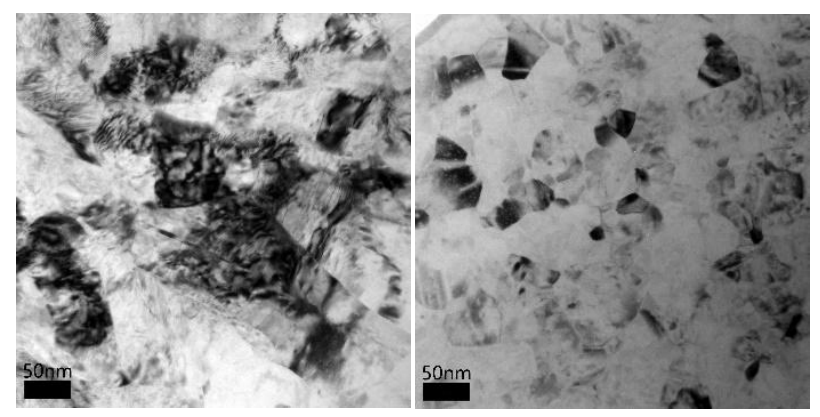

